\title{
VİKOR YÖNTEMİ İLE TÜRK BANKACILIK SEKTÖRÜNÜN PERFORMANS ANALIZZi
}

\author{
Seher A.TEZERGIL *
}

\begin{abstract}
Özet
Bankacılık sektörünün etkinliği ve verimliliği, yeni para ve finans piyasalarının en önemli konularından biridir. Günümüzde yaşanan teknolojik gelişmeler, küreselleşme ve yoğun rekabet, bankaları kaynaklarını etkin şekilde kullanmaya, sektörde bulunan rakip bankaların performanslarını göreli olarak değerlendirmeye ve finansal risklerini gözden geçirmek için referans almaları gereken rakiplerini belirlemeye zorlamaktadır. Çalışmada Türk bankacılık sektöründe faaliyet gösteren mevduat bankalarının finansal performanslarının, VIKOR yöntemi ile değerlendirilmesi amaçlanmıștır. 20092013 yılları arasında Türkiye'deki 28 mevduat bankasına ait bilançolardan elde edilen finansal oranlar kullanılarak VIKOR yöntemi ile performans sıralamaları yapılmıştır.
\end{abstract}

Anahtar kelimeler: : Türk Bankacılık Sektörü, Finansal Performans, Performans Değerlendirme, Çok Kriterli Karar Alma Yöntemleri, VIKOR Yöntemi

JEL Sınıflaması: C44, C61, G21, L25

\section{PERFORMANCE ANALYSIS OF THE TURKISH BANKING SECTOR WITH VIKOR METHOD}

\begin{abstract}
The efficiency and the productivity of the banking sector has been one of the major issues in emerging monetary and financial markets. Today, technological developments, globalization and intense competition enforce banks to use their resources efficiently, evaluate the performance of the competitors relatively and determine their competitors to benchmark with a view to consider their financial risks. This study aims to evaluate the financial performance of deposit banks operating in the Turkish Banking Industry using financial variables and the ranking of performances of the 28 Turkish deposit banks were analyzed through VIKOR technique for the period between 2009- 2013.
\end{abstract}

Keywords: Turkish Banking Sector, Financial Performance, Performance Evaluation, Multi-criteria Decision Making Methods, VIKOR Method.

JEL Classification: C44, C61, G21, L25

\footnotetext{
* Yrd.Doç.Dr., Marmara Üniversitesi Bankacilık Sigortacilık Yüksekokulu, Aktüerya Bölümü, stezergil@marmara.edu.tr
} 


\section{Giriş}

Küreselleşme süreciyle birlikte birbirleriyle sınırları bile olmayan ülkeler kolay yön değiştiren sermaye hareketlerinin etkilerini özellikle de finansal sektörde hızla hissetmeye başlamışlardır. Söz konusu etkilerden korunmak arzusu ve finansal sistem içindeki rekabetin artışı ise uluslararası ölçekteki finansal kuruluşların, diğer ülkelerdeki performans ve büyüme potansiyeli olan kuruluşlarla stratejik ortaklıklar içine girmesine zemin hazırlarken, ulusal çapta ise ölçek farklılıklarından dolayı özellikle bankaların kendi içinde birleşme ve devralma stratejilerini hayata geçirmelerine sebep olmaktadır. Ayrıca diğer sektörlerden farklı olarak kaynak dağılımını belirleyen ve finansal aracılık görevini üstlenen bankacılık sektörünün etkin ve verimli çalışması, ülke ekonomisi açısından da büyük önem taşımaktadır. Dolayısıyla ülkelerin ekonomik gelişmesinde merkezi bir konumda bulunan bankaların performanslarının ölçülmesi ve değerlendirilmesi, hem sektör içindeki pozisyonlarını belirlemekte hem de ülke ekonomisi için süreç yönetimlerinde stratejik önem taşımaktadır.

Literatürde bankaların performanslarını değerlendirmeye yönelik yapılan pek çok çalışma mevcut olmakla birlikte VIKOR yönteminin kullanıldığı çalışma sayısı, diğer çok kriterli karar verme metotlarına oranla oldukça azdır. Ertuğrul ve Karakaşoğlu ${ }^{1}$, yapmış oldukları çalışmada, banka şubelerinin performansını ölçmek amacıyla VIKOR yöntemini kullanırken, Wu vd. ${ }^{2}$, AHP ve VIKOR yöntemleri ile banka performansının ölçülmesi amacıyla bulanık ortamda üç bankayı analiz etmişlerdir. Özden ${ }^{3}$ tarafından Türkiye’deki bankalarının performanslarının ölçülmesinde TOPSIS, PROMETHEE, ELECTRE ve VIKOR yöntemleri bir arada kullanılmıştır. Dinçer ve Görener ${ }^{4}$ ise kamu, özel ve yabancı sermayeli bankaları gruplandırılarak, bu grupların finansal performanslarının ölçümünde AHP ve VIKOR yöntemlerini kullanmışlardır.

Bu çalışmanın amacı 2009-2013 yılları arasında Türk finans sektöründe mevcut mevduat bankalarının seçilen finansal oranlar ekseninde performanslarını sıralamaktır. Bu sıralamayı belirlemede çok kriterli karar verme yöntemlerinden birisi olan VIKOR yöntemi kullanılarak elde edilen bilgiler çerçevesinde değerlendirmeler yapmaktır.

1 İ. Ertuğrul - N. Karakaşoğlu, "Banka Şube Performanslarının Vikor Yöntemi İle Değerlendirilmesi”, Endüstri Mühendisliği Dergisi, YA/EM 2008 Özel Sayısı, 20(1), 2008,ss.19-28.

2 H.Y. Wu ve diğerleri, "A Fuzzy MCDM Approach for Evaluating Banking Performance Based on Balanced Scorecard". Expert Systems with Applications, 36(6), 2009, ss.10135-10147.

3 Ü.H Özden, Türkiye’deki Mevduat Bankalarının Performansları: Çok Kriterli Karar Verme Yöntemleri İle Analizi, 1.Baskı, Detay Yayıncilık, Ankara, 2009.

4 H. Dinçer - A. Görener, "Analitik Hiyerarşi Süreci ve Vikor Tekniği ile Dinamik Performans Analizi: Bankacılık Sektöründe Bir Uygulama”, İstanbul Ticaret Üniversitesi Sosyal Bilimler Dergisi, 10(19), 2011, ss.109-127. 


\section{Veri Seti ve Metodoloji}

\section{I. Veri Seti ve Analizde Kullanılan Finansal Oranlar}

Performans en genel anlamda amaçlı, planlanmış bir etkinlik sonucunda elde edilen nicel ve/ veya nitel çıktı olarak tanımlanabilirken hem sektörel hem de kurumsal gelişim için son derece önemli bir kavramdır. Performansı ölçmede kullanılan göstergeler ise; kurumun misyonunu gerçekleştirme sürecinde ortaya koyduğu kısa ve uzun vadeli hedef ve amaçlarına ulaşması için belirlediği değerlendirme ölçütleridir ${ }^{5}$.

Finansal sistemin en önemli parçası olan bankaların performanslarının ölçülmesinde bilanço ve gelir tablolarında yer alan kalemler arasındaki ilişkilerin ve bunların zaman içerisindeki eğilimlerinin belirlenmesinde kullanılan finansal performans göstergeleri temel olarak kullanılmaktadır. Ayrıca finansal performans ölçümü yapılırken, mali tablolardaki mutlak göstergelerden çok, bu tablolarda yer alan kalemler arasındaki ilişkiler daha önemli olmakta ve bu nedenle daha çok iki mutlak performans göstergesi arasında göreli ilişki kuran finansal oranlardan yararlanılmaktadır 6 .

Söz konusu yaklaşım ekseninde bu çalışmada 2009-2013 yılları arasındaki beş yıllık periyod içinde bankalara ait finansal performansı ölçmede ilgili literatür ve konuyla ilgili uzman görüşlerinden yararlanılarak seçilen oranlar Tablo 1'de sıralanmıştır.

Tablo I. Çalışmada Kullanılan Finansal Oranlar

\begin{tabular}{lll}
\hline Ölçtüğü Performans & KOD & Oranlar \\
\hline Sermaye Yeterliliği & ÖZKTA & Özkaynaklar/Toplam Aktifler \\
Bilanço Yapısı & TMEVTA & $\begin{array}{l}\text { Toplam Mevduat /Toplam Aktifler } \\
\text { Likidite }\end{array}$ \\
LAKSB & Likit Aktifler /Kısa Vadeli Borçlar \\
Karlılık & NDKTA & Net Dönem Karı/ Toplam Aktifler \\
& NDKÖZK & Net Dönem Karı/ Özkaynaklar \\
Gelir-Gider Yapısı & FGTA & Faiz Geliri / Toplam Aktifler \\
& FGTG & Faiz Geliri/ Toplam Gelirler \\
& BTASTA & Bankanın Toplam Aktifleri /Sektörün Toplam \\
& & Aktifleri \\
Sektör Payları & BTMSTM & Bankanın Toplam Mevduatı / Sektörün Toplam \\
& & Mevduatı \\
\hline
\end{tabular}

5 N. Çakmak - E. Ocaklı, “Performans Değerlendirmesi Gerekli Midir? Neden?”, Gazi Üniversitesi ÜNAK’06 Bilimsel İletişim ve Bilgi Yönetimi Sempozyumu, 2006,Ankara, s.214.

6 S.Bülbül - A. Köse, “Türk Gıda Şirketlerinin Finansal Performansının Çok Amaçlı Karar Verme Yöntemleriyle Değerlendirilmesi”. Atatürk Üniversitesi İİBF Dergisi, 10. Ekonometri İstatistik Sempozyumu, Özel Sayısı, 2011, s.71. 
Öz kaynaklar/Toplam Aktifler: Bankacıllğa özgü açıklayıcı değişkenler arasında yer alan bu oran banka varlıklarının yüzde kaçının sahip ve ortakları tarafından finanse edildiğini gösterir ve söz konusu oran artması durumunda karlılık performansının artacağı beklenmektedir?

Toplam Mevdua /Toplam Aktifler: Toplam mevduatın likidite, krediler, özel hesaplar, iştirakler, sabit değerler, tahsili gecikmiş alacaklar ve diğer aktiflerin toplamını ifade eden toplam aktiflere oranını ifade eder. Bu oranın yüksek olması karlılık performansını olumlu yönde etkilemektedir.

Likit Aktifler/Kısa Vadeli Borçlar(Asit Test Oranı): Bu oran cari varlıklardan stokların çıkarılmasıyla elde edilen değerin kısa vadeli borçlara bölünmesiyle bulunur8. Oranının payında, paraya çevrilmesi zaman alabilecek kalemlere yer verilmediğinden, cari orana göre daha duyarlı bir ölçü olarak kabul edilir ve l'e yakın olması halinde işletmenin kısa vadeli borç ödeme gücünde bir aksaklık olmayacağ 1 kabul edilir.

Net Dönem Karı/Toplam Aktifler(ROA-AktifKârllık Oranı): Net işletme kârının toplam aktiflere bölünmesiyle hesaplanan bu oran birim varlık (aktif) başına ne kadar kâr edildiğini gösterir. Yatırımın kârlılığını, diğer bir ifadeyle varlıkların ne ölçüde verimli kullanıldığını ifade eder. Aynı sektörde faaliyet gösteren farklı büyüklükteki işletmelerin kârlılık yönünden karşılaştırılmasına imkân verir.

Net Dönem Karı/Özkaynaklar(ROE-Özsermaye KârlllıkOranı): Bu oran işletme sahip ve ortakları tarafından işletmeye sağlanan sermayenin her birimine düşen kar payını gösterir. ROE’nin, hisse senetleri bono ve vadeli mevduat gibi öteki yatırım alternatiflerinin getirileriyle karşılaştırılması yoluyla, yatırımın fırsat maliyeti hesaplanabilir. Böylece alternatif yatırım alanları içinde yatırım kararının doğruluğu hakkında analiz imkanı sağlar ${ }^{10}$.

Faiz Geliri/Toplam Aktif: Net faiz marjı olarak da ifade edilen bu oran bankaların aracıllk maliyetlerini gösteren temel kriter olduğu için büyük önem taşıyan oranlardandır ${ }^{11}$.Bu oran aynı zamanda sistemdeki etkinliğin ölçülmesinde öncü gösterge niteliğindedir. Öyle ki, bu marjın açılması yatırımcıları bankacılık sisteminden uzaklaştırmakta ve mali sektörün gelişmesini olumsuz etkilemektedir.

7 H.Atasoy, "Türk Bankacılık Sektöründe Gelir-Gider Analizi Ve Karlılık Performansının Belirleyicileri”, Türkiye Cumhuriyeti Merkez Bankası, Bankacılık ve Finansal Kuruluşlar Genel Müdürlüğü, 2007, (Uzmanlık Yeterlilik Tezi) s.50.

8 Bülbül ;Köse, a.g.m.s.s6.

9 B.Aktan - B. Bodur "Oranlar Aracılı̆̆ı İle Finansal Durumunuzu Nasıl Çözümlersiniz? Küçük İşletmeler İçin Bir Rehber", Journal of Yasar University, 1(1), 2006,s.58.

10 N. Aydın, Finansal Yönetim, Anadolu Üniversitesi Yayınları Yayın No 1465, 6. Baskı, Eskişehir, 2008.s.55.

11 Y. T, Kaya, “Türk Bankacılık Sisteminde Net Faiz Marjının Modellenmesi”, Bankacılık Düzenleme Ve Denetleme Kurumu, MSPD Çalışma Raporları, No: 2001/4.s.1. 
Faiz Geliri/ Toplam Gelirler: Toplam gelir içinde faiz gelirinin gücünü ifade eden orandır.

Bankanın Toplam Aktifleri / Sektörün Toplam Aktifleri ve Bankanın Toplam Mevduatı / Sektörün Toplam Mevduatı: Bu iki oran da bankanın sektör içindeki payını değerlendirmeye yarayan performans değerlendirme kriterlerinden önemli oranlardandır.

\section{2. Çalışmada Kullanılan Yöntem}

VIKOR yöntemi karmaşık sistemlerde yani birbiriyle çelişebilen kriterlerden oluşan düzenlerde çok kriterli problemlerin çözümü için Opricovic ve Tzeng ${ }^{12}$ tarafından önerilmiş bir karar alma yöntemidir. Bu yöntem, birden çok kriter birlikte değerlendirilip ideal çözüme en yakın olan uygulanabilir çözümlerin üretilmesine ve alternatifler arasından en iyi olanın seçilmesine veya bu alternatiflerin performanslarına göre sıralanmasına olanak sağlar ${ }^{13}$. Karar alma problemlerinde VIKOR yönteminin tercih edilmesinin en temel sebebi; kolay anlaşılır ve uygulanabilir olması ve bunun yanında gerçekçi çözümler üretmesidir ${ }^{14}$. Ayrıca Opricovic ve Tzeng ${ }^{15}$ TOPSIS ve VIKOR yöntemlerinin karşılaştırılmalı analizini yaptıkları çalışmalarında her iki yöntemi karşılaştırmış ve VIKOR yönteminin karar vericilerin fikirlerini daha iyi yansitabildiğini belirtmişlerdir ${ }^{16}$.

VIKOR yönteminin bazı önemli özellikleri aşağıda sıralanmıştır.

- VIKOR ile karar vericilerin fikir ayrılıkları uzlaşılarak çözülebilir olmalıdır.

- Karar verici, ideal çözüme en yakın çözümü kabul etmeye istekli olmalıdır.

- $\quad$ Fayda ile her kriter fonksiyonu arasında doğrusal bir ilişki vardır.

- $\quad$ Alternatifler, belirlenen tüm kriterler için değerlendirilir.

- Karar vericinin tercihleri ağırlıklar ile ifade edilir.

- $\quad$ VIKOR yöntemi, karar vericinin etkileşimli katılımı olmadan başlar, fakat karar verici nihai çözümü onaylamaktan sorumludur.

- Karar verici, nihai çözüme kendi tercihlerini de dahil edebilir.

- VIKOR'la elde edilen çözüm karar vericiler tarafından kabul edilebilirdir. Çünkü

12 S.Opricovic - G.H Tzeng, "Compromise Solution By MCDM Methods: A Comparative Analysis of VIKOR and TOPSIS”. European Journal of Operational Research, 156, 2004,ss.445-455.

13 Ü.H Özden, “AB’ye Üye Ülkelerin ve Türkiye’nin Ekonomik Performanslarına göre Vikor Yöntemi ile Sıralanması”, İstanbul Ticaret Üniversitesi Sosyal Bilimler Dergisi, 11(21), 2012, s.456.

14 H. Dinçer - A. Görener, "Analitik Hiyerarşi Süreci ve Vikor Tekniği ile Dinamik Performans Analizi: Bankacılık Sektöründe Bir Uygulama”, İstanbul Ticaret Üniversitesi Sosyal Bilimler Dergisi, 10(19), 2011, s.110. 
bu yöntem "çoğunluğun" maksimum grup faydasını ve "karşııı" minimum bireysel pişmanlı̆̆ını sağlar.

- VIKOR yöntemi, özellikle sistem tasarımının başında karar vericinin deneyimli olmadığı veya tercihini belirtmeyi bilmediği durumlarda etkili bir yöntemdir.

- VIKOR'da alternatif kümesine yeni bir alternatifin dahil edilmesi (ya da çıkarılması), alternatiflerin sıralamasını değiştirebilir ${ }^{17}$.

VIKOR, uzlaşılmış bir sıralama belirlemeyi ve belirtilen ağırlıklar altında uzlaşılmış ortak çözüme ulaşmayı sağlar ve her alternatifin, bu yöntemle her bir kriter için değerlendirildiği varsayımı altında, ideal alternatife yakınlık değerleri karşılaştırılarak uzlaşılmış sıralama elde edilir $^{18}$. Buradaki uzlaşık çözüm, ideale en yakın uygun çözümdür ve uzlaşma, ortak kabul üzerinde anlaşmaya varmayı ifade eder ${ }^{19}$. Her bir alternatifin her bir kriter için değerlendirildiği varsayımı altında, ideal alternatife yakınlık değerleri karşılaştırılarak uzlaşık sıralamaya ulaşılır²0 Çok kriterli ölçüm için uzlaşık sıralamanın temelini, uzlaşık programlamada toplama fonksiyonu olarak kullanılan Lp ölçütü oluşturur.J tane alternatifin $a_{1}, a_{2}, \ldots, a_{J}$ şeklinde ifade edilmesi durumunda $a_{j}$ alternatifinin $i$ kriterine göre değerlendirme sonucu olarak ifade edilir.

VIKOR yönteminin temelini oluşturan Lp ölçütü ;

$$
L_{p j}=\left\{\sum_{i=1}^{n}\left[w_{i} \frac{f_{i}^{*}-f_{i j}}{f_{i}^{*}-f_{i}^{-}}\right]^{p}\right\}^{1 / p} \quad 1 \leq \mathrm{p} \leq \infty \quad \mathrm{j}=1,2,3, \ldots \ldots \mathrm{J}
$$

şeklinde formülize edilmektedir. "n" burada kriter sayısını göstermektedir.

Bu yöntemde $L_{i j}$ (Eşitlik 5’teki $S_{j}$ ) ve $L_{\infty j}$ (Eşitlik 6'daki $R_{j}$ ) sıralama ölçütünü oluşturmakta kullanılır. Burada maksimum grup faydasını minS 'den elde edilen sonuç ve karşıt görüştekilerin minimum kişisel pişmanlığı ise minR_j'den elde edilen sonuç gösterir.

Ayrıca uzlaşık çözüm olan $\mathrm{F}^{c}$, ideal çözüme yani $\mathrm{F}^{\star ’ a}$ en yakın uygun çözümdür. Daha önce de ifade edildiği gibi anlaşmanın karşlıklı kabulü anlamına gelen uzlaşık terimi, Şekil l'de görüldüğü gibi $\Delta \mathrm{f}_{1}=\mathrm{f}_{1}^{*}-\mathrm{f}_{1}^{\mathrm{c}}$ ve $\Delta \mathrm{f}_{2}=\mathrm{f}_{2}^{*}-\mathrm{f}_{2}^{\mathrm{c}}$ ile ifade edilmektedir ${ }^{21}$.

17 S. Opricovic - G.H. Tzeng, "Extended VIKOR Method in Comparison with Other Outranking Methods", European Journal of Operational Research, 178, 2007,s.517.

18 Opricovic, S. ve G. H. Tzeng, 2007; Özden, AB’ye Üye Ülkelerin ve Türkiye’nin Ekonomik Performanslarına ......2012, a.g.m.s.457.

19 İ. ErtuğruL-N. Karakaşoğlu, N. "Banka Şube Performanslarının Vikor Yöntemi İle Değerlendirilmesi”, Endüstri Mühendisliği Dergisi, YA/EM 2008 Özel Sayıs1, 20/1, 2008,s.21.

20 S. Opricovic - G.H. Tzeng, "Extended VIKOR Method. ,2007, a.g.m.,s.517.

21 A.Yıldız- M. Deveci, “Bulanık VIKKOR Yöntemine Dayalı Personel Seçim Süreci”, Ege Akademik Bakış, 13(4), 2013, s.429. 


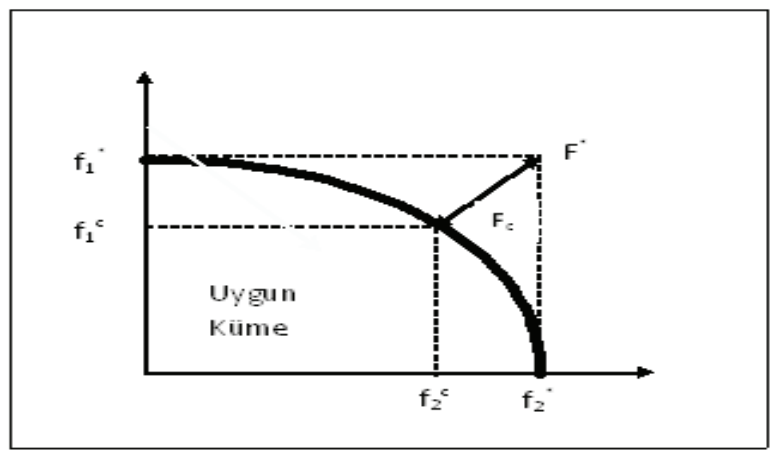

Şekil I. İdeal ve Uzlaşık Çözümler

\section{Uygulama Aşamaları}

1. Aşama: Her bir değerlendirme kriteri için en iyi $\left(f_{i}^{*}\right)$ ve en kötü $\left(f_{i}^{-}\right)$değerler belirlenir. Burada $\mathrm{i}$ karşılaştırma kriterlerini $(\mathrm{i}=1,2,3, \ldots, \mathrm{n})$ ve $\mathrm{j}$ alternatifleri $(\mathrm{j}=1,2,3, \ldots, \mathrm{m})$ göstermektir.

$f_{i}^{*}=\max \left(f_{i j}\right)$ ve $f_{i}=\min \left(f_{i j}\right)$

2. Aşama: Her bir değerlendirme birimi için $\mathrm{S}_{\mathrm{j}}$ ve $\mathrm{R}_{\mathrm{j}}$ değerleri hesaplanır.

wj, toplamları 1 olmak üzere kriter ağırlıklarını temsil etmektedir.

$$
\begin{gathered}
R_{i j}=\frac{f_{i}^{*}-f_{i j}}{f_{i}^{*}-f_{i}^{-}} \\
\mathrm{v}_{\mathrm{ij}}=\mathrm{R}_{\mathrm{ij}} * \mathrm{w}_{\mathrm{j}} \\
\mathrm{S}_{\mathrm{j}}=\sum_{i=1}^{n} V_{i j} \\
\mathrm{R}_{\mathrm{j}}=\max \left[R_{i j}\right]
\end{gathered}
$$

3. Aşama: Her bir değerlendirme birimi için $\mathbf{Q}_{\mathbf{j}}$ değerleri hesaplanır.

Burada $S^{*}=\min S_{j} ; S^{-}=\max S_{j} ; R^{*}=\min _{j} ; R^{-}=\max R_{j}$ değerlerini ifade etmektedir. $v$ değeri, maksimum grup faydasını sağlayan strateji için ağırlı̆̆ı ifade ederken, (-1v) değeri karşıt görüştekilerin minimum pişmanlığının ağırlı̆̆ını ifade etmektedir.

$$
\mathbf{Q}_{\mathrm{j}}=\mathrm{v} \frac{S_{J}-S^{*}}{S^{-}-S^{*}}+(1-\mathrm{v}) \frac{R_{J}-R^{*}}{R^{-}-R^{*}}
$$

Uzlaşma, "çoğunluk oyu" $(v>0,5)$ ile, "konsensus" $(v=0,5)$ ile veya "veto" $(v<0,5)$ ile sağlanabilir. 22 
4.Aşama: $Q_{j}, S_{j}, R_{j}$ değerleri sıralanır. En küçük $Q_{j}$ değerine sahip değerlendirme birimi, alternatif grubu içerisindeki en iyi seçenek olarak ifade edilir.

Sonucun geçerliliği için aşağıda belirtilen koşullar belirleyicidir. Bu koşullar sağlandığında, minimum Q değerine sahip alternatif, en iyi veya en uygun olarak nitelendirilebilir.

\section{Koşul 1 (C1) - Kabul edilebilir avantaj:}

Bu koşul en iyi ve en iyiye en yakın seçenek arasında ciddi bir fark olduğunu ifade eder.

$\mathrm{Q}\left(\mathrm{P}_{2}\right)-\mathrm{Q}\left(\mathrm{P}_{1}\right) \geq \mathrm{D}(\mathrm{Q})$

$\mathrm{P}_{1 \rightarrow}$ en düşük $\mathrm{Q}$ değerine sahip olan birinci en iyi alternatiftir.

$\mathrm{P}_{2 \rightarrow}$ en iyi ikinci alternatiftir.

$D(Q)=1 /(j-1)$ şeklinde ifade edilmektedir.

$\mathrm{j}$, alternatiflerin sayısıdır ve $\mathrm{j}<4$ ise $\mathrm{D}(\mathrm{Q})=0,25 \mathrm{alınır}^{23}$.

\section{Koşul 2 (C2) - Kabul edilebilir istikrar:}

Bu koşulda ise en iyi $\mathrm{Q}$ değerine sahip $\mathrm{P}_{1}$ alternatifi $\mathrm{S}$ ve $\mathrm{R}$ değerlerinin en az bir tanesinde en iyi skoru elde etmiş olmalıdır.

Belirtilen iki koşuldan biri sağlanamazsa uzlaşık çözüm kümesi şu şekilde önerilir:

- 2.Koşul sağlanmıyorsa $P_{1}$ ve $P_{2}$ alternatifleri,

- 1.Koşul sağlanmiyorsa $\mathrm{P}_{1}, \mathrm{P}_{2}, \ldots \ldots, \mathrm{P}_{\mathrm{M}}$ alternatifleri $\mathrm{Q}\left(\mathrm{P}_{\mathrm{M}}\right)$ - $\mathrm{Q}\left(\mathrm{P}_{1}\right) \geq \mathrm{D}(\mathrm{Q})$ eşitsizliği dikkate alınarak ifade edilir. Bu koşulun sağlanamaması bazı alternatifler arasında belirgin bir fark olmadığını ifade eder ${ }^{24}$.

\section{Uygulama}

\section{I. Araştırmanın Amacı, Sınırları}

Küreselleşmenin beraberinde getirdiği yoğun rekabet ortamında bankaların kaynaklarını etkin şekilde kullanmaları, sektörde bulunan rakip bankaların performanslarını göreli olarak değerlendirmeleri ve referans almaları gereken bankaları belirlemeleri finansal risklerini gözden geçirebilmeleri ve stratejiler üretebilmeleri için oldukça önemli bir bilgidir. Dolayısıyla

23 L.Y Chen - T. Wang “Optimizing Partners' Choice İn IS/IT Outsourcing Process: The Strategic Decision Of Fuzzy Vikor”. International Journal of Production Economics, 120(1), 2009, s. 237.

24 Chen -Wang, 2009; Ertuğrul vd.,2009; Özden, “AB’ye Üye Ülkelerin ve Türkiye’nin Ekonomik Performanslarına .....2012, a.g.m.,s.463. 
uygulamada 2009-2013 yılları arasında Türk finans sektöründe yer alan 28 mevduat bankasının finansal performanslarının ölçülerek bankaların sıralanmaları amaçlanmıştır. Finansal performansların belirlenmesinde kriter olarak kullanılan literatür ve konuyla ilgili uzman görüşlerinden yararlanılarak seçilen göstergelere ilişkin oranlar; Türkiye Bankalar Birliği’nin http://www.tbb.org.tr/tr adresinden alınmıștır.

Hesaplamalar 2009-2013 periyodunda her yıl için ayrı ayrı yapılmış olmakla birlikte sadece 2013 yılına ilişkin tablolar örnek teşkil etmesi açısından çalışmada sunulmuştur.

\section{Alternatifler}

2009-2013 periyodunda Türk bankacılık sektöründe yer alan 28 mevduat bankası alternatifler olarak yer almaktadir.

\section{Kriterler}

Tablo 2'deki 9 finansal oran Türkiye Bankalar Birliği'nin verilerinden elde edilen değerler kullanılarak analizde karar kriterleri olarak kullanılmış olup Tablo 3.1'de kriterler tablosu olarak sunulmuştur.

Tablo 2. Kriterler Tablosu

\begin{tabular}{ll}
\hline KOD & Kriterler \\
\hline ÖZKTA & Özkaynaklar/Toplam Aktifler \\
TMEVTA & Toplam Mevduat /Toplam Aktifler \\
LAKSB & Likit Aktifler /Kısa Vadeli Borçlar \\
NDKTA & Net Dönem Karı/ Toplam Aktifler \\
NDKÖZK & Net Dönem Karı/ Özkaynaklar \\
FGTA & Faiz Geliri / Toplam Aktifler \\
FGTG & Faiz Geliri/ Toplam Gelirler \\
BTASTA & Bankanın Toplam Aktifleri /Sektörün Toplam Aktifleri \\
BTMSTM & Bankanın Toplam Mevduatı / Sektörün Toplam Mevduatı \\
\hline
\end{tabular}

Ayrıca, araştırmada performansa negatif etkisi olan kriterlere ilişkin veriler dönüştürme yapılarak pozitif etki sağlayan kriterler gibi analize dahil edilmiştir. Bu dönüştürme işleminde j’inci kriterin yüksek olması (negatif etki yapan) durumunda j’inci kriterin alternatiflere ilişkin maksimum değerinden diğer değerler çıkartılarak

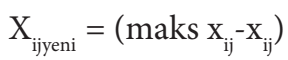

formülü ile elde edilen yeni dönüştürülmüş değerler analizde pozitif etki yapan (olumlu) kriter değerleri gibi kullanılmıştır ${ }^{25}$.

25 Özden, Türkiye’deki Mevduat Bankalarının Performansları,2009, a.g.k.,s.108. 
Analizde maksimum grup faydasını sağlayan strateji için ağırlığı ifade eden “v =0,5” ( konsensüs) olarak ve $\mathrm{w}_{\mathrm{j}}$ ağırlıkları ise eşit yani 9 kriter olması sebebiyle $\mathrm{w}_{\mathrm{j}}=(1 / 9)$ olarak alınmıştır. 2013 yılı için VIKOR yöntemi uygulama adımları aşağıda sunulmuştur.

1. Aşama: $f_{i}^{*}=\max (\mathrm{fij})$ ve $f_{i}^{-}=\min (f i j)$ 'den her kriter için en iyi $f_{i}^{*}$ ve en kötü $f_{i}^{-}$değerleri hesaplandi.

\begin{tabular}{cccccccccc}
\hline \multicolumn{10}{c}{2013} \\
\hline$f \boldsymbol{i}^{\star}$ & 0,925 & 0,802 & 25,757 & 0,085 & 0,264 & 0,109 & 1,355 & 0,1528 & 0,1522523 \\
$f \boldsymbol{i}^{-}$ & 0,057 & 0,027 & 0,313 & 0 & 0 & 0,016 & 0,417 & $6,8 \mathrm{E}-05$ & $9,668 \mathrm{E}-06$ \\
\hline
\end{tabular}

2. Aşama: $\mathbf{R}_{\mathrm{ij}}=\left(\mathbf{f}_{\mathrm{i}}^{*}-\mathbf{f}_{\mathrm{ij}}\right) /\left(\mathbf{f}_{\mathrm{i}}^{*}-\mathbf{f}_{\mathrm{i}}-\mathbf{)}\right.$ (formül 3)'den $\mathrm{R}_{\mathrm{ij}}$ değerleri $\mathrm{j}=1,2, . ., \mathrm{J}$ için hesapland1.

\begin{tabular}{ccccccccc}
\hline & & \multicolumn{7}{c}{ 2013 Rij Değerleri } \\
ZKTA & TMEVTA & LAKSB & NDKTA & NDKÖZK & FGTA & FGTG & BTASTA & BTMSTM \\
\hline 1 & 0,414194 & 0,998153 & 0,847059 & 0,25 & 0,892473 & 0,883795 & 0,950409 & 0,964805 \\
0,906682 & 0 & 0,962899 & 0,752941 & 0,329545 & 0,913978 & 0,768657 & 0,984289 & 0,981104 \\
0,96659 & 0,385806 & 0,990607 & 1 & 1 & 1 & 0,944563 & 0,967609 & 0,975869 \\
. &. &. &. &. &. &. &. &. \\
0,963134 & 0,153548 & 0,989781 & 0,741176 & 0,049242 & 0,806452 & 0,681237 & 0 &. \\
0,949309 & 0,105806 & 0,996266 & 0,694118 & 0 & 0,83871 & 0,76226 & 0,325815 & 0,289142 \\
0,958525 & 0,258065 & 0,991314 & 0,788235 & 0,257576 & 0,892473 & 0,862473 & 0,347257 & 0,424777 \\
\hline
\end{tabular}

$\mathbf{w}_{\mathbf{j}}$ ağırıkları kullanılarak $\mathbf{v}_{\mathrm{ij}}=\mathbf{R}_{\mathrm{ij}}{ }^{*} \mathbf{w}_{\mathrm{j}}$ den $\mathbf{v}_{\mathrm{ij}}$ dğerleri hesaplandı.(formül4) $\mathbf{w}_{\mathrm{j}}$ ağırlıkları 9 kriter için eşit (1/9) olarak alındı.

\begin{tabular}{|c|c|c|c|c|c|c|c|c|}
\hline \multicolumn{9}{|c|}{$2013 v_{\mathrm{ij}}$ Değerleri } \\
\hline ÖZKTA & TMEVTA & LAKSB & NDKTA & NDKÖZK & FGTA & FGTG & BTASTA & BTMSTM \\
\hline 0,111111 & 0,046022 & 0,110906 & 0,094118 & 0,027778 & 0,099164 & 0,098199 & 0,105601 & 0,107201 \\
\hline 0,100742 & 0 & 0,106989 & 0,08366 & 0,036616 & 0,101553 & 0,085406 & 0,109365 & 0,109012 \\
\hline 0,107399 & 0,042867 & 0,110067 & 0,111111 & 0,111111 & 0,111111 & 0,104951 & 0,107512 & 0,10843 \\
\hline . & . & . & . & . & . & . & . & . \\
\hline . & . & . & . & . & . & . & . & . \\
\hline . & . & . & . & . & . & . & . & . \\
\hline 0,107015 & 0,017061 & 0,109976 & 0,082353 & 0,005471 & 0,089606 & 0,075693 & 0 & 0 \\
\hline 0,105479 & 0,011756 & 0,110696 & 0,077124 & 0 & 0,09319 & 0,084696 & 0,036202 & 0,032127 \\
\hline 0,106503 & 0,028674 & 0,110146 & 0,087582 & 0,02862 & 0,099164 & 0,09583 & 0,038584 & 0,047197 \\
\hline
\end{tabular}

3. Aşama: $\operatorname{Toplam}\left(\mathbf{v}_{\mathrm{ij}}\right)$ 'den(formül 5) $\mathbf{S}_{\mathrm{j}}$, Maksimum( $\left.\mathbf{v}_{\mathrm{ij}}\right)^{\prime} \operatorname{den}\left(\right.$ formül 6) $\mathbf{R}_{\mathrm{j}}$, ve (formül 7)'den $\mathbf{Q}_{\mathbf{j}}$ değerleri hesaplandi. 


\begin{tabular}{cccccccccccc}
\hline \multicolumn{10}{c}{2013} \\
\hline Si & 0,800099 & 0,733344 & 0,91456 & 0,677313 &. &. &. & 0,487175 & 0,55127 & 0,6423 \\
Ri & 0,111111 & 0,109365 & 0,111111 & 0,107984 &. &. &. & 0,109976 & 0,110696 & 0,110146 \\
Qi & 0,869156 & 0,513695 & 1 & 0,228797 &. &. &. & 0,32988 & 0,518372 & 0,534442 \\
\hline
\end{tabular}

4. Aşama: $Q_{j}, S_{j}, R_{j}$ değerleri sıralanır. En küçük $Q_{j}$ değerine sahip değerlendirme birimi, alternatif grubu içerisindeki en iyi seçenek olarak ifade edilir. Sonucun geçerliliği için iki koşul sağlanıp sağlanmadığının sınaması yapılarak performans sıralamaları ve uzlaşık çözüm kümeleri oluşturuldu.

\subsection{Bulgular}

Dördüncü aşama sonucunda ulaşılan bulgulara göre en iyi performans gösteren banka 2013 yllında Citibank iken 2012 ve 2011'de Ziraat 2010 ve 2009'da ise Akbank olduğu görülmektedir. bkz.(Tablo 3.) Ziraat bankasının son beş yılda performans olarak hep ilk dört içinde olduğu, Akbank’n ise 2012 hariç diğer dört yılda ilk üç içinde performans gösterdiği görülmektedir. Citibank’in 2009-2012 döneminde ilk 10-20 aralığında performans gösterirken 2013 yılında birinci sırada olması çalışmada kullanılan kriterler ekseninde değerlendirildiğinde faiz gelirlerinin toplam gelirler içindeki payının ve net dönem karının toplam aktifler içindeki payının artışı ile izah edilebilir. Söz konusu yılda Citibank’’n faiz gelirinin sektör ortalamasının yaklaşık 2 katı olduğu görülmektedir.

Ayrıca Tablo 3'den Ziraat, Akbank, Garanti, Yapı Kredi, Halk, Vakıflar, İş Bankası ve Finansbank’ın son beş yıl içinde çalışma kriterleri ekseninde yapılan performans sıralamasında genellikle ilk beş içinde yer aldığg görülmektedir. 
Tablo 3. Mevduat Bankaların VIKOR Yöntemi ile Performans Sıralama Sonuçları (2009-20I3)

\begin{tabular}{|c|c|c|c|c|c|c|c|c|c|}
\hline & 2013 & & 2012 & & 2011 & & 2010 & & 009 \\
\hline$Q j$ & Şirketler & $Q j$ & Şirketler & $Q j$ & Sirketler & $Q j$ & Şirketler & $Q j$ & Sirketler \\
\hline 0,229 & Citibank & 0,152 & Ziraat & 0,033 & Ziraat & 0,152 & Akbank & 0,048 & Akbank \\
\hline 0,330 & Ziraat & 0,352 & Denizb & 0,276 & Halk & 0,258 & Garanti & 0,498 & Ziraat \\
\hline 0,385 & Akbank & 0,387 & Finans & 0,353 & Akbank & 0,309 & Finans & 0,666 & İş \\
\hline 0,442 & Garanti . & 0,405 & Halk & 0,356 & Garanti & 0,330 & Ziraat & 0,668 & Garanti \\
\hline 0,498 & Yapı Kredi & 0,480 & Anadolub & 0,364 & Anadolub & 0,352 & İş & 0,674 & JPMorgan \\
\hline 0,500 & JPMorgan & 0,488 & JPMorgan & 0,382 & Finans & 0,369 & Vakıflar & 0,694 & Halk \\
\hline 0,514 & Arap Türk. & 0,516 & Garanti & 0,432 & ING Bank & 0,526 & Denizb & 0,733 & Vakıflar \\
\hline 0,518 & Halk. & 0,530 & Vakıflar & 0,450 & İş & 0,569 & Halk & 0,775 & Yapı Kredi \\
\hline 0,534 & Vakıflar. & 0,531 & İș & 0,471 & Denizbank & 0,605 & HSBC & 0,784 & Royalbank \\
\hline 0,578 & HSBC & 0,547 & TEB & 0,503 & Vakıflar & 0,620 & JPMorgan & 0,786 & Finans \\
\hline 0,609 & İș & 0,575 & Citibank & 0,507 & TEB & 0,647 & ING & 0,798 & ING \\
\hline 0,669 & Finans & 0,576 & Royal B & 0,555 & HSBC & 0,649 & TürkEkon & 0,819 & Denizbank \\
\hline 0,692 & Denizb & 0,586 & Deutsche & 0,559 & Yapı Kredi & 0,707 & Şekerbank & 0,823 & Anadolu \\
\hline 0,700 & TEB & 0,618 & Akbank & 0,559 & Habib Bank & 0,725 & Citibank & 0,825 & Şekerbank \\
\hline 0,708 & Anadolu & 0,643 & Yapı Kredi & 0,561 & Bank Mellat & 0,749 & Habib & 0,859 & HSBC \\
\hline 0,724 & Royal B & 0,720 & Fibabank & 0,609 & Deutsche & 0,750 & SociétéG & 0,866 & TürkEkono \\
\hline 0,725 & ING & 0,720 & ING & 0,647 & JPMorgan & 0,753 & Anadolu & 0,872 & Alternatif \\
\hline 0,746 & Turkland & 0,730 & HSBC & 0,662 & Royal. & 0,765 & Yapı Kredi & 0,882 & Habib \\
\hline 0,749 & Deutsche. & 0,732 & Tekstil & 0,696 & Arap Türk & 0,780 & Royal & 0,888 & Citibank \\
\hline 0,770 & Bank Mellat & 0,732 & Bank Mellat & 0,701 & Tekstil. & 0,871 & Arap Türk & 0,894 & Turkland \\
\hline 0,773 & Fibabank & 0,775 & Habib & 0,732 & Citibank & 0,873 & Tekstil & 0,896 & Bank \\
\hline 0,797 & SociétéG & 0,799 & Şekerbank & 0,738 & Alternatif & 0,904 & Turkish & 0,898 & Fibabank \\
\hline 0,809 & Turkish & 0,827 & Arap Türk. & 0,752 & Turkland & 0,916 & Bank t & 0,910 & Arap Türk \\
\hline 0,811 & Habib & 0,855 & Turkland & 0,827 & Şekerbank & 0,917 & Deutsche. & 0,914 & Tekstil \\
\hline 0,817 & Şekerbank & 0,899 & SociétéG & 0,850 & SociétéG & 0,931 & Turkland & 0,942 & Turkish \\
\hline 0,869 & Alternatif & 0,926 & Turkish & 0,907 & Burgan & 0,964 & Burgan & 0,989 & Deutsche. \\
\hline 0,871 & Tekstil & 0,983 & Burgan & 0,972 & Fibabank & 0,966 & Alternatif & 0,989 & SociétéG \\
\hline 1,000 & Burgan & 1,000 & Alternatif & 0,990 & Turkish & 0,969 & Fibabank & 0,995 & Burgan \\
\hline
\end{tabular}

Tablo 3'deki çıtılar ekseninde bankaların performans sıralamaları mevcut durumu daha iyi yorumlayabilmek için aşağıdaki şekilde düzenlenmiştir. 
Tablo 4. Performans Sıralama Tablosu

\begin{tabular}{|c|c|c|c|c|c|}
\hline \multicolumn{6}{|c|}{ Siralamalar } \\
\hline Şirketler & 2013 & 2012 & 2011 & 2010 & 2009 \\
\hline Citibank & 1 & 10 & 21 & 14 & 19 \\
\hline Ziraat & 2 & 1 & 1 & 4 & 2 \\
\hline Akbank & 3 & 14 & 3 & 1 & 1 \\
\hline Garanti & 4 & 7 & 4 & 2 & 4 \\
\hline Yapı ve Kredi & 5 & 15 & 13 & 18 & 8 \\
\hline JPMorgan & 6 & 6 & 17 & 10 & 5 \\
\hline Arap Türk & 7 & 23 & 19 & 20 & 23 \\
\hline Halk. & 8 & 4 & 2 & 8 & 6 \\
\hline Vakıflar & 9 & 8 & 10 & 6 & 7 \\
\hline HSBC & 10 & 18 & 12 & 9 & 15 \\
\hline İş & 11 & 9 & 8 & 5 & 3 \\
\hline Finans Bank & 12 & 3 & 6 & 3 & 10 \\
\hline Denizbank & 13 & 2 & 9 & 7 & 12 \\
\hline TEB & 14 & 10 & 11 & 12 & 16 \\
\hline Anadolubank & 15 & 5 & 5 & 17 & 13 \\
\hline Royal Bank & 16 & 12 & 18 & 19 & 9 \\
\hline ING Bank & 17 & 17 & 7 & 11 & 11 \\
\hline Turkland & 18 & 24 & 23 & 25 & 20 \\
\hline Deutsche. & 19 & 13 & 16 & 24 & 26 \\
\hline Bank Mellat & 20 & 20 & 15 & 23 & 21 \\
\hline Fibabanka & 21 & 16 & 27 & 28 & 22 \\
\hline SociétéGénéral & 22 & 25 & 25 & 16 & 27 \\
\hline Turkish Bank & 23 & 26 & 28 & 22 & 25 \\
\hline Habib Bank & 24 & 21 & 14 & 15 & 18 \\
\hline Şekerbank & 25 & 22 & 24 & 13 & 14 \\
\hline Alternatifbank & 26 & 28 & 22 & 27 & 17 \\
\hline Tekstil & 27 & 19 & 20 & 21 & 24 \\
\hline Burgan & 28 & 27 & 26 & 26 & 28 \\
\hline
\end{tabular}

Uzlaşık çözüm kümeleri,(ideal çözüme en yakın uygun çözümü verecek küme) bir diğer ifadeyle karşılıklı kabul gören uygun çözüm kümeleri yıllar itibarıyla Tablo 4’de sunulmuştur. Bu kümelerdeki bankalar kabul edilebilir avantaj ve/veya kabul edilebilir istikrara sahip bankalardır ve Şekil 2.1'deki F'nin altında kalan alanda yer almaktadırlar. 2013 yılında uzlaşık çözüm kümesinde yer alan Citibank*, Ziraat Bankası ve Garanti Bankası* hem kabul edilebilir avantaja 
hem de istikrara sahipken bu kümedeki diğer bankalar ilk koşulu sağlayarak kabul edilebilir avantaja sahiptirler. Diğer yıllarda da * ile işaretli bankalar, grupları içinde diğerlerine göre hem kabul edilebilir avantaja hem de istikrara sahipken diğerleri kabul edilebilir avantaja sahiptirler.

Tablo 4'den çalışmada kullanılan 9 finansal oran ekseninde yapılan performans sıralamasında 3 kamu bankasının araştırma döneminde ilk 10 içinde yer aldığı görülmektedir. Ayrıca Halk Bankası, Ing Bank, Anadolu Bank ve Yapı Kredi Bankası'nın 2011 krizinde performansını arttıran bankalar olduğu görülmektedir.

Tablo 5. Uzlaşık Çözüm Kümeleri Tablosu

\begin{tabular}{|c|c|c|c|c|}
\hline \multicolumn{5}{|c|}{ Uzlaşık çözüm kümeleri } \\
\hline 2009 & 2010 & 2011 & 2012 & 2013 \\
\hline Akbank * & Akbank * & Ziraat Bankası* $^{*}$ & Ziraat Bankası & Citibank A.Ş.* \\
\hline Ziraat Bankası & Garanti Bankası & Halk Bankası & Denizbank & Ziraat Bankası* \\
\hline İş Bankası & Finans Bank A.Ş. & Akbank & Halk Bankası & Akbank \\
\hline Halk Bankası. ${ }^{*}$ & Vakıflar Bankası & Finans Bank & Anadolubank & Garanti Bankası * \\
\hline Vakıflar Bankası * & Denizbank & ING Bank & Yapı ve Kredi.* & Vakıflar Bankası \\
\hline Yap1 ve Kredi & Halk Bankası & Türk Ekonomi & Bank Mellat & HSBC Bank A.Ş. \\
\hline Turkish Bank * & Türk Ekonomi & HSBC Bank & Habib Bank & İş Bankası \\
\hline Deutsche Bank & Şekerbank & Bank Mellat & Turkland Bank & Finans Bank \\
\hline Société Générale & Royal Bank & Deutsche Bank & Société Générale & Şekerbank \\
\hline \multirow[t]{6}{*}{ Burgan Bank } & Arap Türk & JPMorgan & Turkish Bank & Alternatifbank \\
\hline & Akbank & Turkland Bank & Burgan Bank & Tekstil Bankası \\
\hline & & Şekerbank & & Burgan Bank \\
\hline & & Société Générale * & & \\
\hline & & Burgan Bank * & & \\
\hline & & Fibabanka * & & \\
\hline
\end{tabular}

\section{Sonuç}

Teknolojik gelişmelerle küçülen dünyada küresel ve ulusal finans piyasalarında önemli bir güce sahip olan bankacılık sektörü için söz konusu sektörün unsurları olan bankaların performanslarının ölçülmesi, yoğun rekabet ortamında sürdürülebilir bir kalkınma için stratejiler 
üretmede önemli bilgiler vermektedir. Uluslararası veya ulusal düzeyde stratejik ortaklık, birleşme veya devralma kararları vermede bankaların performanslarının ölçülmesi önemli ve belirleyicidir. Söz konusu yaklaşımla bu çalışmada 2009-2013 yılları arasında Türk bankacılık sektöründe bankaların seçilen finansal rasyolar ekseninde performanslarını değerlendirmek için VIKOR yöntemine dayanan bir yaklaşım ele alınmıştır.

Türkiye'de faaliyet gösteren 28 mevduat bankasının (Özkaynaklar/Toplam Aktifler), (Toplam Mevduat/Toplam Aktifler), (Likit Aktifler /Kısa Vadeli Borçlar), (Net Dönem Karı/ Toplam Aktifler), (Net Dönem Karı/Özkaynaklar), (Faiz Geliri/Toplam Aktifler), (Faiz Geliri/ Toplam Gelirler), (Bankanın Toplam Aktifleri /Sektörün Toplam Aktifleri), (Bankanın Toplam Mevduatı/ Sektörün Toplam Mevduatı) oranları ekseninde performans sıralamaları yapılmıştır. Bankaların performanslarının değerlendirilmesi kriter bazında değil, tüm kriterler açısından bir bütün olarak yapılmıştır. Vikor yöntemi karar vericilere; performans değerlendirmede daha fazla önem verdikleri kriterlere daha yüksek, nispeten az önemli gördükleri kriterlere de daha düşük ağırlık vererek sıralamaya yön verebilme imkanı tanıyan bir çok amaçlı karar verme yöntemidir. Dolayısıyla uzun/kısa dönemde bankanın performanslarını değerlendirmede kullanılan kriterlere verilecek ağırlıklar piyasa koşulları sebebiyle değişiklik göstermesi durumunda bir sonraki değerlendirmede ağırlıklar yeniden gözden geçirilerek sıralamalar yenilenebilir. Kriz dönemleri öncesi ve sonrası bu oranalar değişebileceği gibi özelde şirket politikalarının bir sonucu olarak da ağırlıklandırmalar farklılık gösterebilir. Çalışmada her bir kriter eşit (1/9) ağırlı̆̆a sahip varsayımıyla değerlendirilmiştir. VIKOR ile yapılan sıralama sonuçlarına göre 2013 yılında Citibank birinci sırada iken 2012 ve 2011 'de Ziraat 2010 ve 2009'da ise Akbank'in seçili oranlar ekseninde en iyi performans gösterdiği görülmektedir (Tablo 3.2). Ziraat Bankasının ise son beş yılda performans olarak hep ilk dört içinde olduğu, Akbank’ın 2012 hariç diğer dört yılda ilk üç içinde performans gösterdiği görülmektedir. Ayrıca Ziraat, Akbank, Garanti, Yapı Kredi, Halk, Vakıflar, İş Bankası ve Finansbank’ın son beş yıl içinde çalışma kriterleri ekseninde yapılan performans sıralamasında genellikle ilk beş içinde yer aldığı görülmektedir. Uzlaşık çözüm kümeleri, (ideal çözüme en yakın uygun çözümü verecek küme) incelendiğinde ise 2013 yılında Citibank, Ziraat Bankası ve Garanti Bankası hem kabul edilebilir avantaja hem de istikrara sahipken bu kümedeki diğer bankaların (Akbank, Vakıflar Bankası, HSBC, İş Bankası, Finans Bank, Şekerbank, Alternatifbank, Tekstil Bankası, Burgan Bank) ilk koşulu sağlayarak kabul edilebilir avantaja sahip oldukları görülmektedir(Tablo3.3). Çalışmada kullanılan 9 finansal oran ekseninde yapılan performans sıralamasında 3 kamu bankasının araştırma döneminde ilk 10 içinde yer aldığı görülmektedir. Ayrıca Halk Bankası, Ing Bank, Anadolu Bank ve Yapı Kredi Bankasının 2011 krizinde performansını arttıran bankalar olduğu görülmektedir.

Elde edilen sonuçlar ile bankaların sektördeki durumları değerlendirildiğinde genel olarak tutarlılık görülmüş olması sebebiyle Vikor yönteminin bankalar arasında performans sıralamaları elde etmede uygulanabilir bir yöntem olduğuna işaret etmektedir. Ayrıca ideal çözüme yakınlığın ölçüsü olan sıralama indeksini esas alan VIKOR yöntemi, alternatifler arasındaki sıralamanın yanında uzlaşı çözüme de ulaşma imkanı tanır. Bu da ideal çözümden uzak olsa da, bu kümede yer alan bankaların kabul edilebilir performansa sahip olduğunu işaret eder. 
Bankalar, performans değerlendirme sistemlerini etkin hâle getirebildikleri farklı yaklaşım ve yöntemlerle değerlendirmeleri çeşitlendirebildikleri ölçüde sektörü ve kendilerini daha sağlıklı yorumlayabileceklerdir. Bu da daha doğru ve hızlı karar alma ve strateji üretim/ yönetim süreçleriyle birlikte başarıyı beraberinde getirecektir. Bununla birlikte analizlerin ve değerlendirmelerin olabildiğince objektif ve kendi içinde tutarlı temellere dayanması halinde ancak sağlıklı uygulamalar mümkün olacaktır. Burada da en kritik karar performansın hangi kriterlerle ölçüleceği ve kriterlerin hangi oranda performansa etki edeceği kararıdır. Gelecek çalışmalarda söz konusu finansal oranlar çeşitlendirilebileceği gibi bu oranlara müşteri memnuniyeti, personel tatmini, imaj gibi finansal olmayan değerlerle de performans sıralamalarının yapılması mümkündür. 


\section{Kaynakça}

AKTAN B., Bodur B., “Oranlar Aracılığı İle Finansal Durumunuzu Nasıl Çözümlersiniz? Küçük İşletmeler İçin Bir Rehber”, Journal of Yasar University, 1(1), 2006, ss.49-67

ATASOY, H., “Türk Bankacılık Sektöründe Gelir-Gider Analizi Ve Karlılık Performansının Belirleyicileri”, Türkiye Cumhuriyeti Merkez Bankası, Bankacılık ve Finansal Kuruluşlar Genel Müdürlügüu, 2007 ss.1-87 (Uzmanlık Yeterlilik Tezi).

AYDIN, N., Finansal Yönetim, Anadolu Üniversitesi Yayınları Yayın No 6 ,1465. Baskı, Eskişehir, 2008.

BÜlBÜL, S., Köse, A., "Türk Gıda Şirketlerinin Finansal Performansının Çok Amaçlı Karar Verme Yöntemleriyle Değerlendirilmesi”, Atatürk Üniversitesi İİBF Dergisi, 10. Ekonometri İstatistik Sempozyumu, Özel Sayıs1, 2011, ss.71-97.

CHEN, L.Y., Wang T., “Optimizing Partners' Choice in IS/IT Outsourcing Process: The Strategic Decision Of Fuzzy Vikor", International Journal of Production Economics, 120(1), 2009, ss. 233-242.

ÇAKMAK, N., Ocaklı E., “Performans Değerlendirmesi Gerekli Midir? Neden?”, Gazi Üniversitesi ÜNAK’06 Bilimsel İletişim ve Bilgi Yönetimi Sempozyumu, 2006, Ankara, ss. 212-230.

DINÇER, H., Görener, A., “Analitik Hiyerarşi Süreci ve Vikor Tekniği ile Dinamik Performans Analizi: Bankacılık Sektöründe Bir Uygulama”, İstanbul Ticaret Üniversitesi Sosyal Bilimler Dergisi, 10(19), 2011, ss.109-127.

ERTUĞRUL, İ., Karakaşoğlu, N. "Banka Şube Performanslarının Vikor Yöntemi İle Değerlendirilmesi”, Endüstri Mühendisliği Dergisi, YA/EM 2008 Özel Sayısı, 20(1), 2008, ss.19-28.

KAYA, Y. T., “Türk Bankacılık Sisteminde Net Faiz Marjının Modellenmesi”, Bankacılık Düzenleme Ve Denetleme Kurumu, MSPD Çalışma Raporları, No: 2001/4, 2001.

OPRICOVIC, S., Tzeng, G.H., "Compromise Solution By MCDM Methods: A Comparative Analysis of VIKOR and TOPSIS”, European Journal of Operational Research, 156, 2004, ss.445-455.

OPRICOVIC, S., Tzeng, G.H., "Extended VIKOR Method in Comparison with Other Outranking Methods", European Journal of Operational Research, 178, 2007, ss.514-529.

ÖZDEN, Ü. H., Türkiye'deki Mevduat Bankalarının Performansları: Çok Kriterli Karar Verme Yöntemleri İle Analizi, 1.Baskı, Detay Yayıncılık, Ankara, 2009.

ÖZDEN, Ü.H., “AB’ye Üye Ülkelerin ve Türkiye’nin Ekonomik Performanslarına göre Vikor Yöntemi ile Siralanması”, İstanbul Ticaret Üniversitesi Sosyal Bilimler Dergisi, 11(21), 2012, ss.455-468.

WU, H.Y., Tzeng, G.H., Chen, Y.H., "A Fuzzy MCDM Approach for Evaluating Banking Performance Based on Balanced Scorecard". Expert Systems with Applications, 36(6), 2009, ss.10135-10147.

YILDIZ, A. ve Deveci, M. "Bulanık VİKOR Yöntemine Dayalı Personel Seçim Süreci”, Ege Akademik Bakış, 13(4), 2013, ss. 427-436.

YU, P. L. “A Class of Solutions for Group Decision Problems”, Management Science, 19(8),1973, ss.936-946. 
